\title{
Climatology of Aerosol Radiative Properties in the Free Troposphere
}

E. Andrews ${ }^{1,2}$, J.A. Ogren ${ }^{1}$, P. Bonasoni ${ }^{3}$, A. Marinoni ${ }^{3}$, E. Cuevas ${ }^{4}$, S. Rodriguez ${ }^{4,5}$, J.Y. Sun ${ }^{6}$, D. J affe ${ }^{7}$, E. Fischer ${ }^{7}$, U. Baltensperger ${ }^{8}$, E. Weingartner ${ }^{8}$, M. Collaud Coen ${ }^{9}$, S.

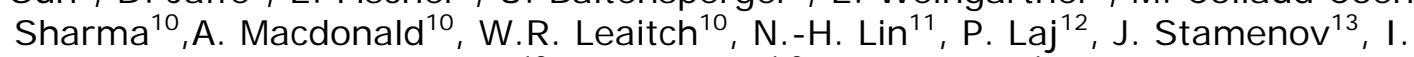
Kalapov $^{13}$, A. Jefferson ${ }^{1,2}$, P. Sheridan ${ }^{1}$

${ }^{1}$ National Oceanic and Atmospheric Agency, Earth Systems Research Laboratory, Boulder, Colorado, 80305, USA

${ }^{2}$ University of Colorado, CIRES, Boulder, Colorado, 80305, USA

${ }^{3}$ Institute of Atmospheric Sciences and Climate, National Research Council, Bologna I-40129, I taly

${ }^{4}$ Izaña Atmospheric Research Centre, AEMET, J oint Research Unit with CSIC "Studies on Atmospheric Pollution", 38071, Santa Cruz de Tenerife, Canary Islands, Spain

${ }^{5}$ University of Huelva, J oint Research Unit with CSIC "Studies on Atmospheric Pollution", 38071, Santa Cruz de Tenerife, Canary Islands, Spain

${ }^{6}$ Key Laboratory for Atmospheric Chemistry, Centre for Atmosphere Watch and Services, Chinese Academy of Meteorological Sciences, China Meteorological Administration, Beijing 100081, China

${ }^{7}$ University of Washington, Department of Atmospheric Sciences, Seattle, 98195, Washington, USA

${ }^{8}$ Paul Scherrer Institute, Laboratory of Atmos. Chem., Villigen PSI, CH-5232, Switzerland

${ }^{9}$ Federal Office of Meteor. and Climatology, MeteoSwiss, CH-1530 Payerne, Switzerland

${ }^{10}$ Environment Canada, Toronto, Ontario, M3H 5T4, Canada

${ }^{11}$ Department of Atmospheric Sciences, National Central University, Chung-Li 320, Taiwan

${ }^{12}$ Laboratoire de Glaciologie et Géophysique de I'Environnement, University of Grenoble, 38402 St Martin d'Hères Cedex, France

${ }^{13}$ Institute for Nuclear Research and Nuclear Energy, Sofia BG-1784, Bulgaria

Keywords: aerosol radiative properties, free troposphere, climatology.

High altitude mountaintop observatories provide the opportunity to study aerosol properties in the free troposphere without the added expense and difficulty of making airborne measurements. Over the last several decades the number of mountaintop observatories continuously measuring in-situ aerosol radiative properties has increased significantly from a single station (Mauna Loa, USA) in the 1970's to at least ten observatories actively making these measurements today. By taking this data set as a whole and developing a self-consistent climatology, the combined observatory measurements of free tropospheric aerosol radiative properties have the potential to contribute to aerosol-climate research in a way that far exceeds the contribution from individual observatories. For example, this type of analysis may help constrain chemical transport models, validate satellite measurements, and quantify the influence of smoke and dust episodes on free troposphere aerosol properties.

Here we present statistics of means, variability, and trends of aerosol radiative properties, including light scattering, light absorption, light extinction, single scattering albedo, Ångström exponent, hemispheric backscatter fraction and radiative forcing efficiency, from various high altitude measurements. These climatologies utilize data from ten mountaintop observatories in the 20-50N latitude band: Mauna Loa, USA; Lulin Mountain, Taiwan; Pyramid, Nepal; Izaña, Spain; Mount Waliguan, China; Beo Moussala, Bulgaria; Mount Bachelor, USA; Monte Cimone, Italy; J ungfraujoch, Switzerland; Whistler Mountain, Canada. Results are also included from two multi-year, in-situ aerosol vertical profiling programs: Southern Great Plains, USA and Bondville, USA. Figure 1 shows the monthly climatology of free troposphere aerosol scattering at Mauna Loa observatory. Figure 1 clearly shows the well-documented (e.g., Perry et al., 1999) effect of long range transport from Asia in the springtime months. For Figure 1 and for all stations included in 
this study, the climatology values are filtered to remove data taken during upslope conditions and for time periods influenced by the presence of clouds.

Using this cloud- and boundary layer contamination- screened data set we address the following questions:

(1) What are the similarities and differences in the means, variability and trends of free-tropospheric aerosol radiative properties at a wide range of locations?

(2) What is the relative importance of aerosol amount and aerosol optical properties for direct radiative forcing calculations? Delene and Ogren (2002) showed that the amount of aerosol was of primary importance while the aerosol optical properties were of secondary importance to direct radiative forcing calculations for the four boundary layer sites they studied.

(3) How do these in-situ climatologies of free tropospheric light extinction compare to the satellite-derived climatologies presented by Kent et al., 1998?

(4) Do aerosol events (e.g., smoke transport) have a significant influence on climatological values?

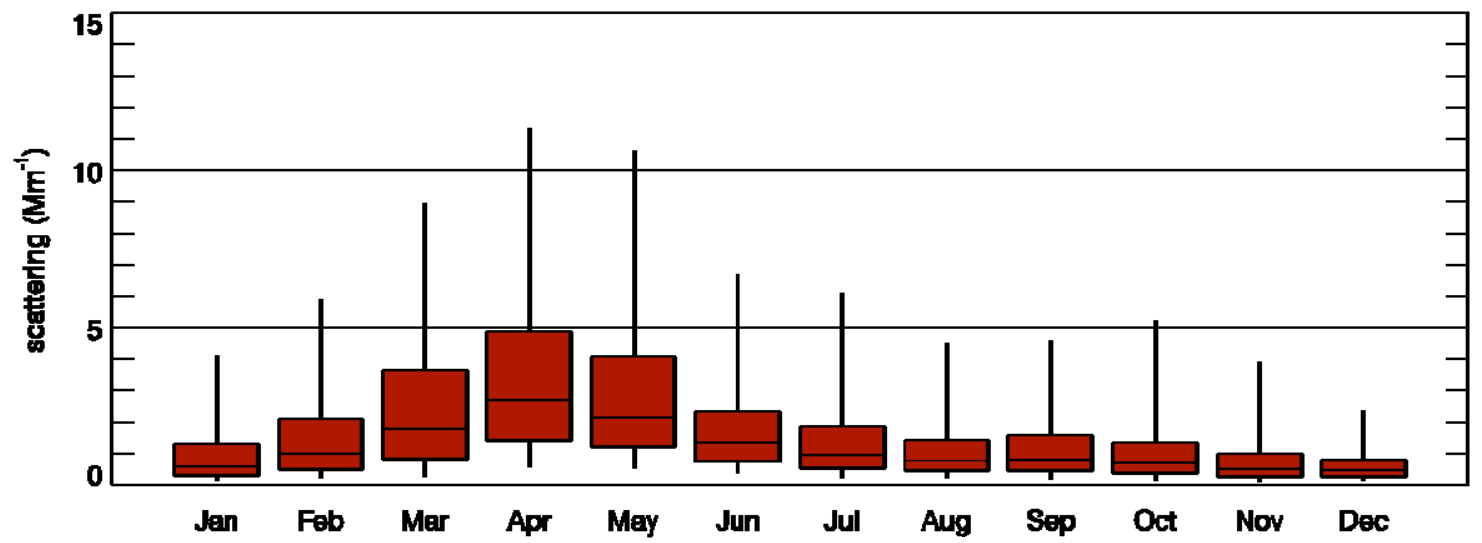

Figure 1. Monthly climatology of aerosol scattering at Mauna Loa (1974-2009), USA. Center line of box represents median value; edges of box are the $25^{\text {th }}$ and $75^{\text {th }}$ percentiles and ends of whiskers are the $5^{\text {th }}$ and $95^{\text {th }}$ percentiles.

Perry K.D., Cahill T.A., Schnell R.C., and Harris, J.M., J. Geophys. Res., 104(D15), 18521-18533, 1999.

Kent, G. S., Trepte, C.R. and Lucker, P.L., J. Geophys. Res., 103(D22), 28,863-28,874, 1998.

Delene D.J., and Ogren, J.A., J. Atmos. Sci., 59, 1135-1150, 2002. 